\title{
Relationship between the nursing practice environment and the therapeutic relationship in acute mental health units: a cross-sectional study
}

\begin{abstract}
The therapeutic relationship constitutes the central axis of mental health nursing. The clinical practice environment has been empirically related to the quality of care. However, the relationship between the two constructs is unknown in the setting of mental health units. We aimed to examine whether the practice environment and nurses' characteristics influence the therapeutic relationship in mental health units. Through a cross-sectional design, data were collected via an online form completed by nurses in 18 mental health units. Linear regression was used to examine the relationship between the clinical practice environment and the therapeutic relationship. Questionnaires were completed by 198 participants. The mean age was 33.8 (SD 9.1) years, 71.7\% were women, and only $20.2 \%$ had a specialist qualification in mental health. The therapeutic relationship was better when there was a more favorable practice environment ( $B$ : 3.111; 95\% CI: 1.46-4.75). The most influential environment-related factor was the nursing foundations for quality of care (B: 2.124; 95\% CI: 0.17-4.07). The factors associated with a high-quality therapeutic relationship were a more favorable practice environment and the presence of more foundations for quality nursing care, coupled with higher academic attainment and longer nursing experience. Institutions should take into account the importance of the nursing practice environment in mental health units. Aspects related to the quality of nursing foundations, such as training, the use of nursing language and taxonomy, and the existence of a common nursing philosophy are influential for a high-quality therapeutic relationship.
\end{abstract}

KEY WORDS: clinical practice nursing research, environment, evidence-based nursing, nurse-patient relationships, mental health nursing 


\section{INTRODUCTION}

The therapeutic relationship (TR) is accepted as the cornerstone of care and as a vehicle to improve the health of people with mental health needs (Zugai et al. 2015). Effectively establishing and maintaining the TR is complex, especially in mental health inpatient units and involuntary settings. Therefore, there is a need to establish optimal conditions that guarantee protected spaces encouraging high-quality interaction between nurses and patients (Gerace et al. 2016; Molin et al. 2018). One of the factors most frequently cited in the literature as hampering the establishment of an adequate TR is the clinical practice environment (Copanitsanou et al. 2017; Felton et al. 2018; Moreno-Poyato et al. 2016). The "practice environment" is defined by Lake (2002) as all the organsational factors that facilitate or hamper nursing practice. The aim of the present study was to examine the association between the clinical practice environment and the TR in mental health units.

\section{BACKGROUND}

The concept of the TR has progressively developed in parallel with the growth and professionalization of mental health nursing, becoming the cornerstone of nursing practice (Gabrielsson et al. 2016; McAndrew et al. 2014; Zugai et al. 2015). A rational construction of mental health nursing has been mainly developed by Peplau, who conceptualised the therapeutic purpose of the nurse-patient relationship (O'Brien 2001). For nurses in mental health units, the therapeutic relationship is defined as a helping relationship, nurse-patient relationship, the trusting relationship, or therapeutic alliance. There is always interpersonal engagement that aims to help patients enhance their wellbeing. The TR is a meaningful relationship between the nurse and patient, with 
therapeutic purposes, in which a therapeutic alliance is established, based on mutual trust (Moreno-Poyato et al. 2016).

A literature review found that the main quality needed by nurses engaged in the TR is empathy (Gerace et al. 2018). Other important qualities are acceptance of the patient, authenticity, and the professional's self-awareness and self-knowledge (Rogers 1972). In particular, users of the service valued a humanistic care model, wanted to be treated kindly, and appreciated professionals' availability and sense of humor. Therefore, patients hoped that nurses could see beyond their illness and engage with them as persons (Hawamdeh \& Fakhry 2014; Wyder et al. 2015).

Moreover, there is evidence that a good TR is associated with better health outcomes for patients, enhances the effectiveness of interventions in inpatient mental health care, and improves both patients' wellbeing and experience (Moreno-Poyato et al. 2017). It also helps to maintain a recovery-oriented focus and reduces professionals' stress levels (Molin et al. 2018). However, the TR does not seem to be a priority in mental health units. Patients often feel that they have few opportunities to work together with staff and perceive a tense and insecure atmosphere in these units (Moreno-Poyato et al. 2016; Pazargadi et al. 2015).

To evaluate the TR in clinical practice, the empirical literature has reported various measurement instruments such as the Working Alliance Inventory (WAI), the Scale to Assess Therapeutic Relationship (STAR), the Helping Alliance Scale (HAS), and the California Psychotherapy Alliance Scale (CALPAS). However, the most widely used instrument to measure the TR is the Working Alliance Inventory Short (WAI-S). This is the instrument that has been translated to the greatest number of languages and has the largest amount of data on its reliability in distinct populations (Harris \& Panozzo 2019). 
The WAI-S evaluates the degree of therapeutic alliance through factors such as the development of an affective bond, mutual agreement on treatment goals, and finally, agreement on the tasks or interventions to be performed ( Horvath \& Greenberg 1989).

Previous studies have identified the factors that help or hinder profesional nursing practice (Kurjenluoma et al. 2017; Pazargadi et al. 2015; Wyder et al. 2015). First, the strong biomedical focus in mental health inpatient units does not always allow nurses to attend to their recovery-oriented function (Wyder et al. 2017). Nurses implementing person-centered care plans can sometimes feel frustrated when physicians change the direction of care (Felton et al. 2018). In this regard, nurses may feel frustrated and distressed when the reality of care does not match their notion of dignified care (Gabrielsson et al. 2016). Moreover, nurses mention an overload of work as a barrier to providing good-quality care (McAndrew et al. 2014). They also highlight the lack of nursing staff and the constant increase in administrative duties that limit the time available for other activities (Engström et al. 2015; Felton et al. 2018; Moreno-Poyato et al. 2016). Another factor is the lack of material resources for therapies and activities for inpatients (Wyder et al. 2017).

Mental health nurses have related their lack of job satisfaction with the policies and organisational design of the institutions where they work. In this regard, the results of other studies support Kanter's theory of structural empowerment in organizations (1993). This theory holds that structural conditions, such as access to opportunities and resources, are among the most important features for staff wellbeing and the effectiveness of organizations (Engström et al. 2015).

Nurses stress the importance of clinical supervision. Therefore, they believe that the support of managers and recognition by them is particularly useful in conflict 
management and in managing the daily workload (Gabrielsson et al. 2016; Gerace et al. 2018; Zugai et al. 2015). Nurses also value written acknowledgment of work well done to increase job satisfaction and increase staff retention (Redknap et al. 2016). Similarly, leaders identified the increasing administrative workload as hampering their ability to provide the support structures required by frontline nurses (Wyder et al. 2017). Finally, nurses also mention the importance of forming part of a team and having the support of all its members as well as of creating spaces for communication to encourage continuity and quality of care (Zugai et al. 2015).

The instrument most widely used internationally to measure nurses' working culture, climate and environment is the Practice Environment Scale of the Nursing Work Index (PES-NWI), which includes factors such as nurses' involvement in the center's affairs, nursing foundations for a high standard of care, nurse managers' ability, leadership and support of nurses, staffing and resource adequacy and, finally, nurse-physician relationships (Lake 2002).

Despite the evidence on the relationship between the practice environment and quality of care, very little literature has been published in the inpatient setting in mental health. Indeed, we found no studies relating the two constructs: the TR and the practice environment for mental health nurses. Therefore, there is a need for more in-depth study of this phenomenon and to identify the environmental factors perceived by nurses as influencing the TR and hampering recovery-oriented care and shared decision-making.

The aims of this study were the following: (1) to describe quality of the TR established by nurses and assess the nursing practice environment in mental health units; (ii) explore possible associations with nurses' main sociodemographic and 
profesional variables; and (iii) examine the effects of the nursing practice environment and nurses' sociodemographic and profesional factors on the TR.

\section{METHODS}

\section{Design and participants}

Cross-sectional data were gathered as part of a mixed methods project consisting of a quasi-expermental design and participatory-action research (title: MiRTCIME.CAT), aiming to enhance the TR by implementing evidence-based practices in acute mental health units in Catalonia (Spain).

The 21 acute mental health units forming part of the Catalan Mental Health Network were informed of the project and 18 units consented to participate. All nurses in these units were informed of the project ( $\mathrm{n}=235)$, of whom 198 finally accepted to participate in the study. Trainee specialist nurses were excluded from the study.

\section{Data collection}

\section{Procedure}

Together with the research team, the management of each unit selected, in a consensusbased manner, a nurse coordinator in each center who showed qualities of leadership and credibility in the eyes of the rest of the group and who accepted to participate voluntarily in the research project. Subsequently, to recruit participants in each unit, first the main investigator presented the project and its aims in each unit and then the nurse coordinators included the volunteer participants, obtaining informed consent forms and e-mail addresses, which would be used to send participants a confidential code together with a link to an electronic data collection form. Data collection for this part of the project was carried out from February to April 2018. 


\section{Measures}

The electronic form included a questionnaire with the nurses' sociodemographic and profesional data and measurement instruments, including the Work Alliance Inventory Short (WAI-S) and the Practice Environment Scale of the Nursing Work Index (PESNWI).

The dependent variable was the TR. The quality of this outcome was measured through the WAI-Short. This version of the scale contains 12 items and each element is evaluated by the health staff using a scale from 1 (never) to 7 (always). The questionnaire is composed of three subscales (i) bond: patient-nurse rapport, which includes aspects such as empathy, mutual trust, and acceptance; (ii) goals: agreement on the goals of therapy (that is, mutual agreement on what the treatment aims to achieve), and (iii) tasks or activities: agreement between the nurse and patient on the tasks or activities that should be carried out. The higher the score, the better the TR. The Spanish version of the WAI-S has good reliability and validity, with a Cronbach's alpha of 0.93 (Andrade-González \& Fernández-Liria 2015).

The perceived nursing practice environment was measured with the PES-NWI (Lake 2002), which contains 31 items assessed on a Likert scale from 1 to 4 points (1= completely disagree, $2=$ disagree, $3=$ agree, and $4=$ completely agree). These 31 items are grouped in 5 subscales: (i) nurse involvement in the center's affairs, which refers to the participatory role and status assigned to nurses in the broad hospital context, (ii) nursing foundations for quality of care, which stress nursing foundations for highquality patient care, (iii) nurse manager ability, leadership and support for nurses, which stresses the fundamental role of nurse managers, (iv) staffing and resource adequacy, which refers to the need for sufficient human and other resources to provide high- 
quality care, and v) nurse-physician relations, referring to the need for collegial relations relaciones. In the adaptation and validation of the scale to Spanish by Pedro-Gómez et al. (2009), Cronbach's alpha values for each of the factors were $.849, .829, .916, .871$ and .807 respectively.

\section{Statistical analysis}

Quantitative variables are expressed as the mean (standard deviation). Categorical variables are expressed as frequency and percentatge. In the bivariate analysis, the association between quantitative variables was evaluated using Pearson's correlation coefficient. The association between categorical variables and quantitative variables was evaluated using Student's T-test.

Because the normality assumption was met for our outcome ( $P$-value for Kolmogorov-Smirnov $=0.200$ ), multiple linear regression models were used to analyze the TR according to assessment of the environment, introducing the variables of nurses' sociodemographic and professional characteristics as potential confounders. Statistical significance was set at $\mathrm{P}<0.05$. The statistical analyses were run using the SPSS V 22.0 statistical package (SPSS Inc., Chicago, IL).

\section{Ethical considerations}

The study was approved by all the hospitals ethics committees', and participating nurses signed a consent form. The consent forms and the completed questionnaire were separated, and data were treated confidentially.

\section{RESULTS}

\section{Description of the sample}


Participants' sociodemographic and professional characteristicss are shown in Table 1. The mean age was 33.8 (SD 9.1) years. In all, $71.7 \%$ were women and only $17.7 \%$ were mental health specialists. The average number of years of experience was 7.8 (SD 7.4). Only $33.3 \%$ had a PhD or Master's degree. Almost $40 \%$ of the nurses had a rotating shift and the rest worked a fixed shift.

\section{Quality of the therapeutic relationship}

The mean score for the quality of the TR among nurses was $62.2(\mathrm{SD}=5.8)$. The highest scored factor was the bond, with a mean of $23.1(\mathrm{SD}=2.3)$, while the mean score for agreement on tasks and goals was $20.2(\mathrm{SD}=2.7)$ and $18.9(\mathrm{SD}=2.7)$, respectively. In the analysis of the relationship between nurses' sociodemographic and profesional characteristics and the quality of the TR, the only significant correlations were found for age $(\mathrm{r}=0.143, P=0.044)$ and years of experience working in mental health $(\mathrm{r}=0.221$, $P<0.01)$. In addition, significant differences were found in the quality of the TR between nurses with a diploma/undergraduate degree and those with a postgraduate degree $(\mathrm{t}=-2.345,95 \% \mathrm{CI}=(-3.559,-0.305) ; P=0.020)$.

\section{Assessment of the clinical practice work environment}

Nurses rated their work environment with a mean score of $2.55(\mathrm{SD}=0.5)$. The highest rated element was leadership and support from nurse managers, with 2.9 points $(\mathrm{SD}=0.8)$. Foundations for high-quality care and collegial nurse-physician relationhip also scored above the neutral value of $2.7(\mathrm{SD}=0.6)$ and the mean score of $2.5(\mathrm{SD}=0.7)$. The worst rated factors were nurse involvement in hospital affairs with $2.4(\mathrm{SD}=0.6)$ points and adequate staff and resources, with $2.1(\mathrm{SD}=0.6)$ points. Analysis of the participants' sociodemographic and profesional variables and their relationship with 
nurses' perception of their clinical practice environment showed statistically significant correlations between age $(\mathrm{r}=-0.281, P<0.0001)$ and years of experience working in mental health $(\mathrm{r}=-0.202, P<0.01)$. Specialist nurses generally rated the work environment more poorly than non-specialist nurses $(\mathrm{t}=-2,090,95 \% \mathrm{CI}=(-11.273,-$ 0.239); $P=0.041)$.

\section{Relationship between the TR, work environment, and participants' sociodemographic and professional characteristics}

The analysis of the relationship between perception of the work environment and the factors related to the quality of the TR are shown in Table 2. In general, the results show that nurses established a better TR when they had a more favorable perception of the work environment $(\mathrm{r}=0.203, P<0.01)$. When nurses perceived the work environment more favorably, they established a better bond and agreement on tasks with patients. In particular, nurses perceiving greater participation in the center's affairs, also had the feeling of a stronger bond $(\mathrm{r}=0.164, P=0.021)$ and agreement on tasks with patients $(\mathrm{r}=$ $0.182, P=0.010)$. In centers where nurses perceived more foundations for quality nursing care, there were stronger bonds $(\mathrm{r}=0.197 P<0.01)$, greater agreement on tasks $(\mathrm{r}=0.280 P<0.001)$, and an enhanced perception of the TR in general $(\mathrm{r}=0.247$, $P<0.001)$. There was a positive correlation between assessment of leadership and support for nurses by nurse management and the nurse-patient bond $(r=0.181$, $P=0.011)$. In addition, in centers where nurses perceived more adequate staffing and resources, there was greater agreement on tasks between nurses and patients $(r=0.159$, $P=0.025)$.

The results of the two models used to determine whether the TR can be explained by assessment of the nursing practice environment and participants' sociodemogratic and 
profesional factors are shown in Table 3. The first model, adjusted by age, gender, mental health experience, educational attainment, and specialty qualification, was significant $(P<0.0001)$. Significant variables were educational attainment $(\beta=0.179$, $P<0.01)$, experience $(\beta=0.259, P=0.012)$ and, with greater influence, the practice environment ( $\beta=0.260, P<0.0001)$. In the second model, the aim was to examine the association between the various environment-related factors separately, together with the nurses' sociodemographic and profesional variables and the TR. This model was also significant $(P<0.0001)$. The significant factors were educational attainment, experience, and nursing foundations for quality of care.

\section{DISCUSSION}

The general aim of this study was to examine the association between work environment and the RT in mental health. The results showed a close relationship between the two factors. Although we found no studies that directly examined the association between the RT and nursing practice environment, studies in the field of mental health have shown a link between the professional practice environment and greater nurse dedication to their patients (Bowers et al. 2011; Gabrielsson et al. 2016). Indeed, favorable work environments have been related to nurses' work satisfaction (Farmakas et al. 2014; Kurjenluoma et al. 2017).

The sociodemographic and profesional characteristics of nurses in this study were very similar to those of participants in other studies evaluating the nursing practice environment in other countries (Kurjenluoma et al. 2017; Roche et al. 2011).

First, in workplaces where nurses experienced greater involvement in the center's affairs, they also had a greater sense of bond and agreement with tasks with patients, 
favoring the TR. Likewise, nurses perceiving more foundations for quality nursing care generally also perceived a stronger bond, greater agreement with tasks and more favorable perception of the TR with their patients. In this regard, previous studies have associated work enjoyment and dedication with the practice environment and patients' and nurses' outcomes (Van Bogaert et al. 2012). Indeed, these results are in agreement with those of other studies conducted in the mental health setting showing that the profesional practice environment influences staff vigor, dedication and adaptation and showing more positive results in terms of job satisfaction, intention to stay, and perceptions of quality of care. (Van Bogaert et al. 2012).

The results of this study also show a relationship between nurse manager leadership and support of nurses and the nurse-patient bond. When nurses were more satisfied with the leadership in their centers, they established stronger bonds with their patients. This finding could be because nurses felt more supported by their supervisors, which in turn enhanced their attitude and motivation. Previous studies have stressed the need for managers to acknowledge nurses' work as well as to offer support and feedback (Gabrielsson et al. 2016; Redknap et al. 2016).

In centers where nurses perceived more optimal staffing and resource adequacy, there was greater nurse-patient agreement on tasks. Indeed, one of the organizational barriers repeatedly mentioned in the literature is nurses' lack of time to establish an adequate TR in acute mental health units (Harris et al. 2019; Pazargadi et al. 2015; Felton et al. 2018; Moreno-Poyato et al. 2016). Nurses stress the lack of nursing staff and the constant increase in administrative tasks that take time away from quality relationships (Felton et al. 2018; Moreno-Poyato et al. 2016). Other studies suggest that spending more time with patients positively impacts their recovery (Zugai et al. 2015; Harris et al. 2019). In 
this regard, the results of our study indicate the need to bear in mind the resources offered by an organization to allow high-quality mental health nursing care.

Statistically significant differences were also found in nurse-physician relationships and nurses' perception of the bond and agreement on tasks with patients. Nurses who scored the nurse-physician relationship more highly, generally had a more favorable impression of the RT with their patients. In this regard, it seems obvious that mutual support among staff and creating spaces for daily critical discussion could enhance both the continuity and quality of nursing care (Gabrielsson et al. 2016). The literature has undoubtedly shown that a favorable work environment is associated with quality of care and job satisfaction among nurses (Kurjenluoma et al. 2017; Roche et al. 2011). Moreoever, there is evidence relating high levels of emotional exhaustion with a worse perception of the nurse practice environment (Van Bogaert et al. 2013).

The results of this exploratory analysis of the association between the TR and nurse practice environment also confirm that nurses forged a higher-quality TR with patients when they perceived a better practice environment in general and, moreover, had higher academic qualifications. Indeed, when environment-specific factors were incorporated into the model, the factors most closely associated with a high-quality TR were nursing foundations for quality of care and nurses' length of experience. Academic qualifications are often cited in the literature as strongly influencing quality of care (McAndrew et al. 2014; Roche et al. 2011). However, only 1\% of the sample in this study had a doctorate and most did not have a specialist qualification in mental health. These findings agree with those of other studies performed in mental health units (Farmakas et al. 2014; Kurjenluoma et al. 2017; Roche et al. 2011), indicating the need to increase awareness of evidence-based practice and promote its implementation to 
enhance the factors contributing to a high-quality TR (Moreno-Poyato et al. 2017). The TR could also be enhanced by greater nursing experience, more security and self confidence among nurses and therefore greater perception of an adequate TR with their patients. However, we found no studies exploring this association in the setting of mental health.

The results of this study support Kanter's theory (1993) on the importance of contextual factors such as access to resources and information and staff support by management for adequate staff performance. It seems obvious that in those centers where nurses perceived a more favorable working environment, better results can be obtained in terms of outcomes, greater bond and agreement on tasks with patients. However, the most important factor related to the practice environment in our study was not implicitly found within Kanter's model. We found that nursing foundations for quality of care was the factor most strongly influencing the quality of the therapeutic relationship.

\section{Limitations and strengths}

This study has some limitations. First, the cross-sectional design did not allow us to detect changes in nurses' perceptions over time or make causal inferences. Second, the study analysed only nurses' perceptions of the TR, which may have differed from those of their patients. In contrast, a strength of the study is the participation rate among both nurses and centers. In addition, we were able to find specific relationships between the environment and the therapeutic relationship and, although the degree of influence from a predictive point of view is not high, these findings should encourage us to continue indepth study of the factors influencing a quality therapeutic relationship, and also to incorporate the other actors involved. 


\section{CONCLUSION}

This study shows that the factors associated with higher-quality TR in mental health units are a more favorable nurse practice environment and, specifically, the presence of more foundations for quality nursing care, together with higher academic qualifications and longer nurse experience. This is the first time that these factors have been significantly related to the quality of the TR. These findings also confirm the experience of many nurses and highlight the need to design actions to improve the work environment and, in turn, the quality of nursing care in mental health units.

\section{RELEVANCE FOR CLINICAL PRACTICE}

The importance of this study for clinical practice lies in the findings indicating the need to raise nurses' awareness of the importance of the practice environment for the quality of the TR. They should also encourage nurses' to take greater responsibility for their environment and consequently become more involved in shared decision-making.

This study also shows that nurse leaders should ensure that nursing philosophy and methodology are maintained as the central pillar of nursing clinical practice and encourage nurse participation in the center's affairs, ensuring adequate human resources and encouraging good staff relations. Nurse leaders should bolster aspects such as training, the use of nursing language and taxonomy, and the presence of a common nursing philosophy, which influence the quality of the TR. Nurse managers could use the results of this study to establish objectives to improve nurses' job satisfaction, which would in turn enhance the quality of nursing care in mental health units.

\section{REFERENCES}

Andrade-González, N., \& Fernández-Liria, A. (2015). Spanish Adaptation of the Working Alliance Inventory-Short (WAI-S). Current Psychology, 35(1), 169-177. 
https://doi.org/10.1007/s12144-015-9365-3

Bowers, L., Nijman, H., Simpson, A., \& Jones, J. (2011). The relationship between leadership, teamworking, structure, burnout and attitude to patients on acute psychiatric wards. Social Psychiatry and Psychiatric Epidemiology, 46(2), 143148. https://doi.org/10.1007/s00127-010-0180-8

Copanitsanou, P., Fotos, N., \& Brokalaki, H. (2017). Effects of work environment on patient and nurse outcomes. British Journal of Nursing, 26(3), 172-176. https://doi.org/10.12968/bjon.2017.26.3.172

De Pedro Gómez, J., Morales Asencio, J. M., Sesé Abad, A., Bennasar Veny, M., Artigues Vives, G., \& Pericàs Beltran, J. (2009). Validación y adaptación al español de la escala del entorno de práctica enfermera del Nursing Work Index (Spanish validation and adaptation of the Nursing Work Index scale of nursing practice). Metas de Enfermería, 12(7), 65-75.

Engström, M., Westerberg Jacobson, J., \& Mårtensson, G. (2015). Staff assessment of structural empowerment and ability to work according to evidence-based practice in mental health care. Journal of Nursing Management, 23(6), 765-774. https://doi.org/10.1111/jonm.12206

Farmakas, A., Papastavrou, E., Siskou, O., Karayiannis, G., \& Theodorou, M. (2014). Challenges in mental health nursing: Working in institutional or community settings? Journal of Psychiatric and Mental Health Nursing, 21(1), 39-45. https://doi.org/10.1111/jpm.12045

Felton, A., Repper, J., \& Avis, M. (2018). Therapeutic relationships, risk, and mental health practice. International Journal of Mental Health Nursing, 27(3), 11371148. https://doi.org/10.1111/inm.12430

Gabrielsson, S., Sävenstedt, S., \& Olsson, M. (2016). Taking personal responsibility: Nurses' and assistant nurses' experiences of good nursing practice in psychiatric inpatient care. International Journal of Mental Health Nursing, 25(5), 434-443. https://doi.org/10.1111/inm.12230

Gerace, A., Oster, C., O’Kane, D., Hayman, C. L., \& Muir-Cochrane, E. (2018). Empathic processes during nurse-consumer conflict situations in psychiatric inpatient units: A qualitative study. International Journal of Mental Health Nursing, 27(1), 92-105. https://doi.org/10.1111/inm.12298

Harris, B. A., \& Panozzo, G. (2019). Therapeutic alliance, relationship building, and communication strategies-for the schizophrenia population: An integrative review. Archives of Psychiatric Nursing, 33(1), 104-111. https://doi.org/10.1016/j.apnu.2018.08.003

Hawamdeh, S., \& Fakhry, R. (2014). Therapeutic relationships from the psychiatric nurses' perspectives: An interpretative phenomenological study. Perspectives in Psychiatric Care, 50(3), 178-185. https://doi.org/10.1111/ppc.12039

Horvath, A. O., \& Greenberg, L. S. (1989). Development and validation of the Working Alliance Inventory. Journal of Counseling Psychology, 36(2), 223-233.

Kanter, R. M. (1993). Men and women of the corporation. New York: Basic Books.

Kurjenluoma, K., Rantanen, A., McCormack, B., Slater, P., Hahtela, N., \& Suominen, T. (2017). Workplace culture in psychiatric nursing described by nurses. Scandinavian Journal of Caring Sciences, 31(4), 1048-1058. https://doi.org/10.1111/scs.12430

Lake, E. T. (2002). Development of the practice environment scale of the Nursing Work Index. Research in Nursing \& Health, 25(3), 176-88. 
https://doi.org/10.1002/nur.10032

McAndrew, S., Chambers, M., Nolan, F., Thomas, B., \& Watts, P. (2014). Measuring the evidence: reviewing the literature of the measurement of therapeutic engagement in acute mental health inpatient wards. International Journal of Mental Health Nursing, 23(3), 212-20. https://doi.org/10.1111/inm.12044

Molin, J., Lindgren, B., Graneheim, U. H., \& Ringnér, A. (2018). Time Together: A nursing intervention in psychiatric inpatient care: Feasibility and effects. International Journal of Mental Health Nursing, 27(6), 1698-1708. https://doi.org/10.1111/inm.12468

Moreno-Poyato, A. R., Delgado-Hito, P., Suárez-Pérez, R., Leyva-Moral, J. M., AceñaDomínguez, R., Carreras-Salvador, R., ... Montesó-Curto, P. (2017).

Implementation of evidence on the nurse-patient relationship in psychiatric wards through a mixed method design: study protocol. BMC Nursing, 16(1), 1-7. https://doi.org/10.1186/s12912-016-0197-8

Moreno-Poyato, A. R., Montesó-Curto, P., Delgado-Hito, P., Suárez-Pérez, R., AceñaDomínguez, R., Carreras-Salvador, R., ... Roldán-Merino, J. F. (2016). The Therapeutic Relationship in Inpatient Psychiatric Care: A Narrative Review of the Perspective of Nurses and Patients. Archives of Psychiatric Nursing, 30(6), 782787. https://doi.org/10.1016/j.apnu.2016.03.001

O'Brien, a J. (2001). The therapeutic relationship: historical development and contemporary significance. Journal of Psychiatric and Mental Health Nursing, 8(2), 129-137. https://doi.org/10.1046/j.1365-2850.2001.00367.x

Pazargadi, M., Fereidooni Moghadam, M., Fallahi Khoshknab, M., Alijani Renani, H., \& Molazem, Z. (2015). The Therapeutic Relationship in the Shadow: Nurses Experiences of Barriers to the Nurse-Patient Relationship in the Psychiatric Ward. Issues in Mental Health Nursing, 36(7), 551-557. https://doi.org/10.3109/01612840.2015.1014585

Redknap, R., Twigg, D., \& Towell, A. (2016). What interventions can improve the mental health nursing practice environment? International Journal of Mental Health Nursing, 25(1), 42-50. https://doi.org/10.1111/inm.12187

Roche, M., Duffield, C., \& White, E. (2011). Factors in the practice environment of nurses working in inpatient mental health: A partial least squares path modeling approach. International Journal of Nursing Studies, 48(12), 1475-1486. https://doi.org/10.1016/j.ijnurstu.2011.07.001

Rogers, C. R. (1972). El proceso de convertirse en persona (On becoming a person) (17th ed.). Barcelona: Paidós.

Van Bogaert, P., Clarke, S., Wouters, K., Franck, E., Willems, R., \& Mondelaers, M. (2013). Impacts of unit-level nurse practice environment, workload and burnout on nurse-reported outcomes in psychiatric hospitals: A multilevel modelling approach. International Journal of Nursing Studies, 50(3), 357-365. https://doi.org/10.1016/j.ijnurstu.2012.05.006

Van Bogaert, P., Wouters, K., Willems, R., Mondelaers, M., \& Clarke, S. (2012). Work engagement supports nurse workforce stability and quality of care: Nursing teamlevel analysis in psychiatric hospitals. Journal of Psychiatric and Mental Health Nursing, 20(8), 679-686. https://doi.org/10.1111/jpm.12004

Wyder, M., Bland, R., Blythe, A., Matarasso, B., \& Crompton, D. (2015). Therapeutic relationships and involuntary treatment orders: Service users' interactions with health-care professionals on the ward. International Journal of Mental Health 
Nursing, 24(2), 181-189. https://doi.org/10.1111/inm.12121

Wyder, M., Ehrlich, C., Crompton, D., McArthur, L., Delaforce, C., Dziopa, F., ...

Powell, E. (2017). Nurses experiences of delivering care in acute inpatient mental health settings: A narrative synthesis of the literature. International Journal of Mental Health Nursing, 26(6), 527-540. https://doi.org/10.1111/inm.12315

Zugai, J. S., Stein-Parbury, J., \& Roche, M. (2015). Therapeutic Alliance in Mental Health Nursing: An Evolutionary Concept Analysis. Issues in Mental Health Nursing, 36(4), 249-257. https://doi.org/10.3109/01612840.2014.969795 
TABLE1. Participants' sociodemographic and professional characteristics $(n=198)$

\begin{tabular}{|c|c|c|}
\hline Variable & $\mathrm{n}$ & $\%$ \\
\hline Mean age in years (SD) & & \\
\hline \multicolumn{3}{|l|}{ Gender } \\
\hline Male & 56 & 28.3 \\
\hline Female & 142 & 71.7 \\
\hline \multicolumn{3}{|l|}{ MH Nursing Specialty } \\
\hline Yes & 39 & 19.7 \\
\hline No & 159 & 80.3 \\
\hline \multicolumn{3}{|l|}{ Highest education } \\
\hline Bachelor's degree & 132 & 66.7 \\
\hline $\mathrm{PhD}$ or Master's degree & 66 & 33.3 \\
\hline \multicolumn{3}{|l|}{ Work shift } \\
\hline Morning & 36 & 18.2 \\
\hline Afternoon & 49 & 24.7 \\
\hline Night & 36 & 18.2 \\
\hline Rotating & 77 & 38.9 \\
\hline \multicolumn{3}{|l|}{ Employment contract } \\
\hline Permanent & 116 & 81.3 \\
\hline Temporary & 37 & 18.7 \\
\hline Mean years of MH experience (SD) & & \\
\hline
\end{tabular}

SD, standard deviation; MH, mental health 
TABLE 2. Relationship between the nursing practice environment and the quality of the nurse-patient therapeutic relationship

\begin{tabular}{lcccccc}
\hline & Nurse & Nursing & Nurse Manager & Staffing and & Collegial Nurse- \\
Variable & Participation in & Foundations for & Ability, & Resource & Physician & NWI-PES \\
& Hospital Affairs & Quality of Care & Leadership and & Adequacy & Relationships \\
& & & Support of Nurses & & & \\
\hline
\end{tabular}

Bond

$0.164^{*}$

$0.197^{* *}$

$0.181^{*}$

0.133

$0.141^{*}$

$0.225^{* * *}$

Objectives

$-0.022$

0.088

$-0.015$

$-0.037$

0.073

0.018

Tasks

$0.182^{* *}$

$0.280^{* * *}$

0.107

$0.159^{*}$

$0.143^{*}$

$0.233^{* * *}$

WAI-S

0.137

$0.247^{* * *}$

0.113

0.107

$0.155^{*}$

$0.203^{* *}$

$* \boldsymbol{P}<\mathbf{0 . 0 5}, * * \boldsymbol{P}<\mathbf{0 . 0 1}, * * * \boldsymbol{P}<\mathbf{0 . 0 0 1}$. WAI-S, Working Alliance Inventory - Short; NWI-PES: Practice Environment Scale of the Nursing Work Index. Pearson's correlation coefficient 
TABLE 3: Multiple linear regression examining the association between the nursing practice environment and the therapeutic relationship $(n=198)$

\begin{tabular}{|c|c|c|c|c|c|c|}
\hline \multirow[t]{2}{*}{ Variable } & \multicolumn{3}{|c|}{$\begin{array}{c}\text { Model 1 } \\
\text { (Adj } R^{2}=0.127 \text { ) }\end{array}$} & \multicolumn{3}{|c|}{$\begin{array}{c}\text { Model } 2 \\
\left.\text { (Adj } R^{2}=0.122\right)\end{array}$} \\
\hline & B & $95 \%$ CI & $P$-value & B & $95 \% \mathrm{CI}$ & $P$-value \\
\hline Age (years) & 0.058 & -0.072 to 0.188 & 0.379 & 0.055 & -0.085 to 0.175 & 0.495 \\
\hline Gender (female) & 1.151 & -0.587 to 2.889 & 0.193 & 1.091 & -0.790 to 2.695 & 0.282 \\
\hline Years of MH experience & 0.205 & -0.072 to 0.188 & 0.012 & 0.190 & 0.029 to 0.352 & 0.021 \\
\hline $\begin{array}{l}\text { Highest education ( } \mathrm{PhD} \text { or } \\
\text { master's degree) }\end{array}$ & 2.210 & 0.563 to 3.856 & 0.009 & 2.287 & 0.616 to 3.958 & 0.008 \\
\hline MH Nursing Specialty (no) & 1.347 & -0.844 to 3.537 & 0.227 & 1.297 & -0.956 to 3.550 & 0.258 \\
\hline NWI-PES & 3.111 & 1.466 to 4.756 & $<0.0001$ & & & \\
\hline $\begin{array}{l}\text { Nurse Participation in } \\
\text { Hospital Affairs }\end{array}$ & & & & 0.278 & -1.568 to 2.124 & 0.767 \\
\hline $\begin{array}{l}\text { Nursing Foundations for } \\
\text { Quality of Care }\end{array}$ & & & & 2.124 & 0.175 to 4.072 & 0.033 \\
\hline $\begin{array}{l}\text { Nurse Manager Ability } \\
\text { Leadership and Support of } \\
\text { Nurses }\end{array}$ & & & & 0.062 & -1.117 to 1.241 & 0.918 \\
\hline $\begin{array}{l}\text { Staffing and Resource } \\
\text { Adequacy }\end{array}$ & & & & 0.353 & -0.833 to 1.539 & 0.558 \\
\hline $\begin{array}{l}\text { Collegial Nurse-Physician } \\
\text { Relationships }\end{array}$ & & & & 0.576 & -0.718 to 1.870 & 0.381 \\
\hline
\end{tabular}

NWI-PES, Practice Environment Scale of the Nursing Work Index; CI, confidence interval; MH, mental health 